\title{
ICO как современный способ финансирования высокотехнологичных проектов
}

\author{
Е.А. ОБУХОВА, Новосибирский национальный исследовательский \\ государственный университет, Новосибирск. E-mail: e.a.obukhova@gmail.com
}

Привлечение инвестиций является одной из наиболее значимых задач, стоящих перед менеджментом на любой стадии жизненного цикла бизнес-проекта. В последнее время помимо традиционных каналов фандрайзинга широкое распространение получили такие относительно новые способы привлечения финансирования, как краудфандинг и первичное размещение токенов (ICO - initial coin offering). Наиболее часто по этому пути идут команды, задействованные в реализации высокотехнологичных проектов. Возрастающий интерес инвесторов подогревается бурным ростом курса криптовалют, а также политикой ряда ведущих стран, поддерживающих обращение криптовалют и операции с ними.

В настоящей статье сделан обзор мирового опыта проведения ICO, осуществлен SWOT-анализ данного механизма привлечения инвестиций, а также рассмотрены примеры из реальной экономической практики последних лет, иллюстрирующие возможности и ограничения использования данного метода. С учетом проведенного анализа сформулированы несколько сценариев развития технологий создания и использования криптовалют, а также дана оценка перспектив осуществления ICO, основанного на их выпуске.

Ключевые слова: криптовалюта, ICO, блокчейн, биткойн, токен, фандрайзинг, инвестиции, SWOT-анализ

\section{Современные технологии постоянно меняют облик мировой} экономической системы, встраивая в нее все новые элементы. Одним из трендов последних нескольких лет стал бурный рост нового вида цифровых активов - криптовалют.

Криптовалюта, или децентрализованная виртуальная валюта - это основанная на математических принципах с открытым исходным кодом виртуальная валюта, схема эмиссии и учета которой базируется на технологии асимметричного шифрования и различных криптографических методах защиты целостности информации, фиксируемых в технологии блочных цепей блокчейн (block chain). Такая виртуальная валюта не имеет центрального администратора и органа централизованного наблюдения или надзора [Кочергин, 2017]. Примерами децентрализованных виртуальных валют могут служить Bitcoin, Litecoin, Namecoin и т.д. Для обозначения единицы криптовалюты зачастую применяется слово «токен», однако это понятие иногда используется в более широком значении (как единица учета при представлении цифрового баланса в некоем активе).

\section{ICO как способ привлечения инвестиций}

По данным портала coinmarketcap.com, в биржевом обороте по состоянию на 10.09.2017 г. находятся 864 криптовалюты, общая 
капитализация которых составляет около 139,9 млрд долл., при этом на долю топ-10 криптовалют приходится 87\% рыночной капитализации. Это свидетельствует о росте популярности ICO как механизма привлечения инвестиций. По некоторым оценкам, ежедневно происходит выпуск одного нового токена [Пряников и др., 2017$].$

ICO (Initial Coin Offering - первичное предложение или размещение монет) - механизм привлечения инвестиций, основанный на эмиссии компаниями новой криптовалюты (токенов) в обмен на традиционные валюты или иные виды криптовалют, находящиеся в обращении. Вновь созданная криптовалюта компании после процедуры ICO начинает торговаться на бирже и обретает свой курс по аналогии с существующими криптовалютами [Adhami et al, 2017].

Переводя вопрос в практическую плоскость, отметим, что процесс выпуска новой криптовалюты обладает рядом особенностей.

1. «Добыча» новой единицы криптовалюты происходит при помощи достаточно мощного вычислительного оборудования и специального программного обеспечения, что ограничивает потенциальный круг «добывающих» компаний.

2. Максимально возможное количество криптовалюты, которое можно сгенерировать, ограничено алгоритмом, лежащим в ее основе, и является обязательным условием выпуска нового токена. Таким образом, добыча последних единиц криптовалюты значительно усложняется, что позволяет поддерживать баланс ее стоимости

3. Контролирующие органы разных стран по-разному оценивают законность выпуска и сделок с криптовалютой, но в большинстве из них интенсифицируются процессы их легитимизации.

4. Все операции с криптовалютами проводятся через электронные кошельки и являются безвозвратными и анонимными, что предполагает определенные риски для сторон сделки

На сегодняшний день в сети Интернет существует множество специальных ресурсов для генерации новых криптовалют: библиотеки исходных кодов, специализированные программы для их модификации и запуска в блоках сети блокчейн'. Однако процесс выпуска новой валюты не ограничивается технической стороной. Немаловажную роль играют ее позиционирование на рынке, формирование грамотного продвижения, которое зависит от цели выпуска новой криптовалюты. В частности, в зависимости от их предназначения² выделяются токены-жетоны, используемые для оплаты внутренних сервисов проекта; токены-акции дающие право на долю в компании и/или ее прибыли; кредитные токены, позволяющие компании-эмитенту привлечь внешнее финансирование на заранее определенных условиях

Вновь созданные токены начинают торговаться на биржах. Особенностями криптобирж являются анонимность счетов и невозможность заморозки либо аннулирования платежей, а также нерегулируемость со стороны контролирующих органов, но конкретные правила торговли на каждой из них могут различаться ${ }^{3}$. В таблице 1 приведен список десяти крупнейших по объему торгов биткойнами международных бирж (всего их насчитывается около 185)

'Как создать собственную криптовалюту. URL: https://mining-bitcoin.ru/kriptovalyuta/ kak-sozdat-svoyu-kriptovalyutu\#i. (дата обрашения: 10.11.2017); Криптовалюта - как ее создавать? URL: https://habrahabr.ru/post/263367/ (дата обращения: 10.11.2017)

2 Что такое токен ICO. URL: https://rb.ru/howto/chto-takoe-token/ (дата обращения: 20.10.2017).

Топ-10 бирж криптовалют. URL: http://crypto-mining.ru/luchshie-birzhi-kriptovalyutspisok-bitkoin-birzh.html. (дата обращения 15.10.2017).
Таблица 1. Крупнейшие биржевые площадки, работающие с криптовалютами

\begin{tabular}{|l|c|c|c|}
\hline $\begin{array}{c}\text { Наименование } \\
\text { биржи }\end{array}$ & $\begin{array}{c}\text { Количество торговых } \\
\text { пар* }\end{array}$ & $\begin{array}{c}\text { Дата регистрации } \\
\text { домена }\end{array}$ & $\begin{array}{c}\text { Доступ на территории } \\
\text { РФ** }\end{array}$ \\
\hline Bitfinex & 61 & 11.10 .2012 & Нет \\
\hline Poloniex & 102 & 10.01 .2014 & Есть \\
\hline Bitstamp & 1 & 04.07 .2011 & Нет \\
\hline LiveCoin & 293 & 04.03 .2014 & Есть \\
\hline Cex.io & 1 & 30.06 .2013 & Есть \\
\hline LocalBitcoins & 89 & 05.06 .2012 & Есть \\
\hline BitX South Africa & 4 & 01.03 .2013 & Есть \\
\hline Bitkonan & 2 & 12.06 .2013 & Есть \\
\hline OKCoin & 2 & 01.11 .1999 & Есть \\
\hline INDX & H/Д & 28.12 .1998 & Есть \\
\hline
\end{tabular}

Примечание: * Торговые пары (валютные пары) - отношение цен двух валют (базовой и котируемой), входящих в пару на данном валютном рынке (валютной бирже). ${ }^{* \star}$ Согласно ФЗ № 149 «Об информации, информационных технологиях и защите информации".

Источник: bitmakler.com. 2017. 15 окт.

\section{Международный опыт регулирования рынка криптовалют}

Биткойн (BTC) является первой и наиболее широко распространенной криптовалютой. Это полностью децентрализованная система электронных денег. Биткойн имеет открытый программный код, поэтому процесс его майнинга доступен практически каждому и ограничен лишь мощностью вычислительного оборудования, а также ключевым алгоритмом. С момента появления в 2008 г. по настоящее время, по оценке, «добыто» около 60\% всех биткойнов [Роббек, 2014]. Несмотря на возрастающий интерес к данной криптовалюте, процесс майнинга биткойнов будет популярен до тех пор, пока их стоимость превышает совокупные затраты на оборудование и электроэнергию.

Интерес к этой валюте подогревается стремительным ростом обменного курса, который поддерживается, в том числе, за счет взятого правительствами Японии, Кореи и Китая курса на проникновение криптовалют в повседневную жизнь граждан и даже госучреждений (например, для сбора налогов и выставления 
электронных счетов $)^{4}$. Всего за один летний месяц 2017 г. общая капитализация биткойнов возросла почти в два раза и составила 73,5 млрд долл. по состоянию на 16 августа 2017 г. $^{5}$

В ряде стран сейчас предпринимаются попытки построить систему государственного регулирования оборота криптовалют Так, в Германии правовой статус биткойна рассматривается как вариант частных денег, безналичный оборот которых разрешен на всей территории страны. В Японии правительством предпринимаются попытки наладить механизм налогообложения операций в криптовалюте. США рассматривает биткойн как вид имущества, Норвегия - как биржевой актив, а парламент Швейцарии принял решение считать их иностранной валютой. Правительство Венесуэлы 03.12.2017 г. объявило о создании собственной криптовалюты (El Petro) как инструмента преодоления социально-экономического кризиса ${ }^{6}$. Вместе с тем во многих странах, таких как Тайланд, Боливия, Эквадор, оборот криптовалют запрещен законодательно [Кочергин, 2017; Николайчук, 2017].

А Китай, поначалу поддерживавший криптовалюты, в течение августа-сентября 2017 г. изменил свою политику. Так, согласно заявлению Народного банка Китая от 4 сентября 2017 г., в стране запрещено проведение ICO, а компании, уже привлекшие инвестиции таким способом, обязаны вернуть инвесторам денежные средства (по состоянию на июль 2017 г. в КНР было проведено $65 \mathrm{ICO}$, в ходе которых были привлечены инвестиции на общую сумму свыше 394,5 млн долл.) 7 .

Несмотря на внушительные успехи по первичному размещению новых криптовалют, многие эксперты и чиновники полагают, что анонимный характер операций может приводить к их использованию в криминальных целях. В частности, ЦБ РФ в своем заявлении от 4 сентября 2017 г. предупреждает граждан о высоких рисках

${ }^{4}$ China and Japan are largely responsible for cryptocurrency's success. URL: http://www. businessinsider.com/cryptocurrency-china-japan-bitcoin-ethereum-2017-7. (дата обрашения: 02.09.2017).

Азиатский след: за новый взлёт стоимости Bitcoin нужно благодарить Китай, Японию и Корею. URL: https://m.geektimes.ru/company/hashflare/blog/291971/ (дата обращения: 02.09.2017).

${ }^{6}$ Мадуро объявил о создании венесуэльской криптовалюты. URL: https://news.mail ru/politics/31840582/?f=vk. (дата обращения: 05.12.2017).

В Китае запретили ICO, организаторов обязали вернуть средства инвесторам URL: https://m.geektimes.ru/post/292655/. (дата обращения: 05.09.2017). вложения средств в криптовалюту и ограничении ее обращения на территории России ${ }^{8}$

Вместе с тем интерес многих крупных финансовых учреждений к самой технологии блокчейн9 , лежащей в основе механизма обращения криптовалют, может стать базой для разработки новых международных межбанковских финансовых каналов связи, подобных существующей системе SWIFT [Степанова и др., 2016]. В России эта система получила название «технологии распределенного реестра» (distributed ledger technology - DLT). Однако возникает неоднозначная ситуация: вместе с развитием технологии блочных цепей и внедрением ее в банковскую финансовую систему косвенно повышается популярность криптовалют, что в свою очередь создает некую альтернативу существующей финансовой инфраструктуре.

\section{ICO как способ финансирования \\ высокотехнологичных стартапов}

Процесс поиска средств для реализации проектов, особенно высокорисковых, всегда является сложной задачей, требующей от команды активных действий по поиску каналов привлечения средств, составлению грамотного бизнес-плана, а также убеждению инвесторов в потенциальной финансовой успешности их бизнесидеи. В связи с развитием IT-технологий в последние годы все большее распространение получают нетрадиционные средства фандрайзинга, такие как краудфандинг и ICO, которые при грамотном использовании ускоряют процесс поиска инвестиций и делают его открытым для максимально широкого круга заинтересованных лиц. На основании изложенного представляется целесообразным изучение особенностей стремительно обретающего популярность ICO.

По данным интернет-портала CoinDesk, на 25 сентября 2017 г. компании всего мира с 2014 г. привлекли с помощью ICO около 2,377 млрд долл., причем более 87\% (свыше 2 млрд долл.) - с начала 2017 г. ${ }^{10}$ Первым успешным ICO стал выпуск в 2013 г. токенов (новой криптовалюты Mastercoin) и привлечение им инвестиций на сумму свыше 5 млн долл. Самый большой объём инвестиций посредством выпуска токенов был привлечен компанией

${ }^{8}$ ЦБ РФ Об использовании частных «виртуальных валют» (криптовалют). URL: http://www.cbr.ru/press/PR/?file=04092017 183512if2017-09-04T18 31 05.htm. 05.09.2017.

${ }^{9}$ Глобальные банки активно интересуются технологией биткоина. URL: https://www vedomosti.ru/finance/articles/2015/09/16/608882-globalnie-banki-interesuyutsya-bitkoina (дата обращения: 02.09.2017).

${ }^{10}$ All-time cumulative ICO funding. URL: https://www.coindesk.com/ico-tracker/. (дата обращения: 07.10.2017). 
Tezos (альтернативная блокчейн-платформа) в июле 2017 г. (230,5 млн долл.), по данным сайта tokendata.io. Примерами площадок, осуществляющих размещение таких инвестиционных предложений, являются веб-сайты icoalert.com, tokenmarket.net и tokendata.iо и др.

Важно отметить, что особенно чувствительным вопрос привлечения средств становится для инноваторов, осуществляющих высокотехнологичные разработки под руководством венчурных инвесторов в рамках ограниченного бюджета. Механизм ICO является прогрессивным способом привлечения средств: он освобождает команду от излишней отчетности по отношению к источнику вложений и дает мощный старт для развития бизнеса на условиях заимствования. Кроме того, привлечение инвестиций, как правило, особенно ценно в конкретный момент времени и может позволить команде совершить прорыв по сравнению с конкурентами, находящимися в менее выгодном положении из-за осторожного отношения к нетрадиционным способам привлечения средств.

Проанализировав 35 проектов, размещенных на портале tokendata.io, получивших наибольшее финансирование (от 30 до 230,5 млн долл.) посредством ICO, можно сделать вывод о том, что наиболее успешны проекты, напрямую или косвенно связанные с процессами выпуска или обращения криптовалют, а также сделок в криптовалюте. Среди остальных проектов, получивших менее 30 млн долл., встречаются как стартапы, основанные на технологии распределенного реестра (DLT), так и другие высокотехнологичные проекты, а также часть проектов, относящихся к реальному сектору экономики.

Определить точное количество проектов, относящихся к той или иной категории, затруднительно из-за отсутствия необходимого критерия при представлении проекта на агрегирующих интернет-площадках. Однако можно сделать вывод о преобладании на бирже криптовалют токенов высокотехнологичных проектов. Вместе с тем не существует преград для выхода на ICO проектов из реального сектора экономики.

Ключевым отличием процедуры ICO от процедуры IPO является ее нерегулируемый со стороны государственных органов характер и отсутствие правовой базы, гарантирующей инвесторам законность осуществляемой сделки. Кроме того, приобретение токенов не дает инвестору прав на участие в управлении компанией, в отличие от приобретения акций. По своей природе токены ближе к облигациям, построенным на фьючерсных обязательствах. Многими экспертами по финансовым рынкам такая модель оценивается как достаточно прогрессивная ${ }^{11}$.

\section{SWOT-анализ метода ICO}

Нами был проведен SWOT-анализ ICO как метода привлечения финансирования с целью выявления сильных и слабых сторон, а также определения на их основе возможностей и угроз относительно его применения как со стороны инвестора, так и владельца бизнеса (табл. 2, 3).

\section{Таблица 2. SWOT- анализ метода ICO со стороны инвестора}

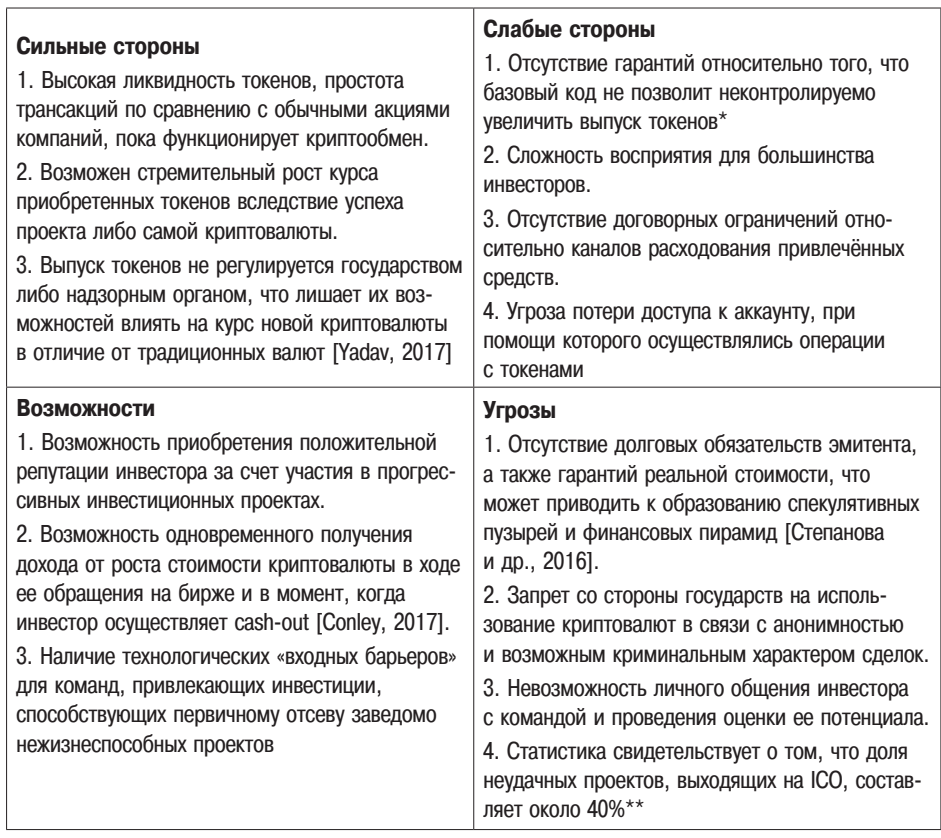

Примечание: *ICO Compelling advantages, real risk. URL: https://www.coindesk com/token-sales-compelling-advantages-real-ris (дата обращения: 12.09.2017). **Токены на ICO дорожают в десятки раз, а Центробанк РФ предупреждает об опасности. URL: https://m.geektimes.ru/post/292669/. (дата обращения: 06.09.2017).

${ }^{11}$ Киргизия первой из стран ЕАЭС выпустит криптовалюту. URL: https://iz.ru/605623/ vladimir-zykov/kyrgyzstan-pervym-iz-stran-eaes-vypustit-kriptovaliutu (дата обращения 05.09.2017); Миллиардер из Японии: ICO расширяет возможности венчурного финансирования. URL: https://forklog.com/milliarder-iz-yaponii-ico-rasshiryayutvozmozhnosti-venchurnogo-finansirovaniya (дата обращения: 23.09.2017). 
Примером реализации отрицательных сценариев может служить значительное падение курса Bitcoin и других ведущих криптовалют в начале января 2018 г. на фоне заявления властей Южной Кореи о намерении полностью запретить оборот виртуальных денег в стране ${ }^{12}$.

\section{Таблица 3. SWOT-анализ метода ICO со стороны бизнеса,} осуществляющего поиск инвестиций

\begin{tabular}{|c|c|}
\hline $\begin{array}{l}\text { Сильные стороны } \\
\text { 1. Возможность быстрого привлечения } \\
\text { значительного объема финансовых } \\
\text { средств. } \\
\text { 2. Отсутствие обязательств со стороны } \\
\text { эмитента по поддержанию оборота } \\
\text { криптовалюты. } \\
\text { 3. Отсутствие необходимостиподготовки } \\
\text { отчетности и проведения аудита } \\
\end{array}$ & $\begin{array}{l}\text { Слабые стороны } \\
\text { 1. Необходимость соблюдения налогового законодательства } \\
\text { страны, в которой зарегистрирована компания-эмитент. При } \\
\text { условии выполнения всех нюансов, выпуск токенов может } \\
\text { оказаться сложнее выпуска акций. } \\
\text { 2. Техническая сложность генерации криптовалюты по срав- } \\
\text { нению с краудфандингом. } \\
\text { 3. Существенная ограниченность круга людей, готовых } \\
\text { участвовать в ІСО }\end{array}$ \\
\hline 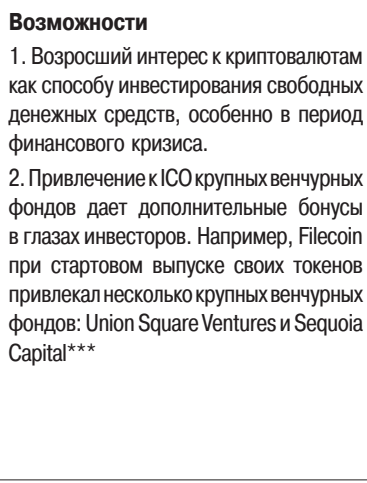 & $\begin{array}{l}\text { Угрозы } \\
\text { 1. Эмитенты не всегда знают тонкости законодательства, } \\
\text { связанного с финансовыми операциями страны, в которой } \\
\text { осуществляется сделка, и могут быть привлечены к ответст- } \\
\text { венности финансовым либо налоговым регулятором, которые } \\
\text { проявляют повышенный интерес к ICO [Venegas et al, 2017]. } \\
\text { Например, в США в июле } 2017 \text { г. Kомиссия по ценны } \\
\text { бумагам приравняла выпуск токенов к первому публичному } \\
\text { размещению традиционных акций }{ }^{\star *} \text {. } \\
\text { 2. Использование в процессе генерации криптовалют спе- } \\
\text { циализированныхресурсов-вычислительного оборудования } \\
\text { иэлектричества, поддерживающегоего непрерывную работу, } \\
\text { побуждает пользователей создавать больше ресурсов для } \\
\text { майнинга, что снижает вероятность атак на систему, но при } \\
\text { этом способствует появлению других систем, использующих } \\
\text { меньше ресурсов [Кочергин, 2017; Шестопалова, 2016]. }\end{array}$ \\
\hline
\end{tabular}

Примечание: * ICO Compelling advantages, real risk. URL: https://www.coindesk. com/token-sales-compelling-advantages-real-ris (дата обращения: 12.09.2017) **B США приравняли блокчейн - ICO к выпуску обычных акций. URL: http:// www.rbc.ru/finances/26/07/2017/5978309f9a7947ab4451167d (дата обращения: 05.09.2017). ${ }^{* \star *}$ Filecoin presale raises $\$ 52$ million ahead of ICO Lunch. URL: https:// www.coindesk.com/filecoin-presale-raises-52-million-ahead-ico-launch (дата обращения: 05.09.2017).

Выделенные глобальные тренды представляется полезным проиллюстрировать рядом примеров из последних событий в сфере мировой политики и экономики, имеющих, зачастую, диаметрально противоположную направленность.

${ }^{12}$ Биткоин подешевел до 13 тыс. долл. URL: https://ria.ru/economy/20180111/1512406326. $\mathrm{html}$ (дата обращения: 12.01.2018).
Так, ярким примером использования возможностей криптовалют для повышения интереса к своему бизнесу и привлечения не только денежных средств, но и увеличения биржевой ценности собственных акций, может служить заявление о планах по выпуску собственной криптовалюты компанией Kodak. После вброса данных сведений в новостные ленты ведущих СМИ акции компании выросли в стоимости на $120 \%{ }^{13}$. Схожим путем идет компания Telegram, владеющая одним из крупнейших мобильных мессенджеров. По сообщениям ряда информационных агентств, эта компания планирует не только выпуск собственной криптовалюты, но и создание собственной блокчейн-платформы третьего поколения. По оценкам экспертов, Telegram планирует привлечь не менее 500 млн долл. только на стадии предпродаж, а в целом, выпуск криптовалюты может принести компании до 5 млрд долл. ${ }^{14}$

Также определенным негативным оттенком обладают появившиеся новости о планах Министерства финансов РФ по внесению изменений в налоговое законодательство, приравнивающих майнинг криптовалют к предпринимательской деятельности. Предполагается, что все осуществляющие его граждане должны зарегистрироваться в качестве индивидуальных предпринимателей и платить налоги с доходов, полученных от оборота криптовалют. В данном случае можно говорить о том, что Россия идет по пути США, где с 1 января 2018 г. все трансакции с криптовалютами облагаются фискальным сбором ${ }^{15}$.

\section{Прогноз развития рынка криптовалют}

Проанализировав различные взгляды экспертов на данную проблему, мы сформулировали три возможных сценария, обобщающих прогнозы дальнейшего развития технологии создания и использования криптовалют, а также основанного на их эмиссии метода ICO.

Оптимистичный: получит развитие ключевая технология, произойдет совершенствование законодательных механизмов регулирования, возникнут необходимые институты, криптовалюты станут легитимным общепризнанным платежным средством, не контролируемым отдельными правительствами. ICO станет широко используемым способом фандрайзинга и будет в дальнейшем развиваться параллельно с совершенствованием технологий.

\footnotetext{
${ }^{13}$ Цифровая лихорадка: зачем компании выпускают собственные криптовалють. URL: https://ria.ru/economy/20180110/1512389234.html (дата обращения: 12.01.2018) ${ }^{14}$ Telegram создаст блокчейн-платформу и криптовалюту. URL: https://ria.ru/ economy/20180109/1512265698.html (дата обращения:10.01.2018).

15 Операция - регистрация: добытчиков криптовалют обложат налогами URL: https://ria.ru/economy/20180109/1511986369.html (дата обращения: 12.01.2018).
} 
Реалистический: по аналогии с «кризисом доткомов» произойдет резкий спад интереса к криптовалютам, который вызовет обвал спроса на проведение ICO, и этот механизм финансирования проектов станет невостребованным.

Пессимистичный: руководствуясь желанием контролировать финансовые потоки и эмиссию валют в целях обеспечения экономической безопасности, правительства большинства государств запретят использование криптовалют, что повлечет отказ от дальнейшего использования метода ICO для привлечения инвестиций, а сами криптовалюты останутся средством осуществления незаконных криминальных трансакций.

Таким образом, пока из-за высокой неопределенности и большого количества трудно поддающихся прогнозированию факторов, влияющих на перспективы развития ICO, достаточно затруднительно делать однозначные выводы.

При этом представляется достаточно обоснованной гипотеза, согласно которой такая неопределенность не сможет длиться достаточно долго, и в ближайшие несколько лет криптовалюты либо приобретут законный статус, либо выйдут из обращения по той или иной причине.

\section{Заключение}

Изменения в мировой экономической системе, вызванные проникновением во все ее элементы высоких технологий, с одной стороны, ставят нас перед лицом новых перспектив, а с другой формируют новые угрозы и ведут к росту неопределенностей как финансового, так и правового характера. Дискуссия относительно перспектив использования криптовалют как платежного средства, a ICO - как способа привлечения инвестиций, по-видимому, будет завершена лишь после окончательного решения вопроса о законодательном регулировании и правовом статусе криптовалют в ведущих государствах мира. На текущий момент представляется, что энтропия данной «финансовой экосистемы» слишком велика для формулирования четких прогнозов. Как и любое состояние неопределенности, оно дает возможность отдельным игрокам «поймать рыбку в мутной воде» (например, тем, кто приобрел биткойны в феврале 2009 г. по цене 1 долл. за единицу, а теперь имеет возможность продавать их по цене свыше
13000 долл.), однако о возможности построения долгосрочной обоснованной стратегии на данном этапе речь идти не может.

Безусловно, в рамках данной статьи рассмотрены лишь основные тенденции существования и развития рынка криптовалют, намечены «широкими мазками» ключевые тренды, возможности и угрозы. Представляют значительный исследовательский интерес такие вопросы, как проведение систематизации и классификации эмитентов криптовалют и инвесторов, использующих ICO, в зависимости от их мотивации и интересов, поиск возможностей и описание особенностей применения ICO в различных отраслях экономики, а также сопоставление институциональных ограничений на осуществление трансакций с криптовалютами в масштабах мировой экономики, которые требуют отдельного исследования.

\section{Литература}

Кочергин Д.А. Место и роль виртуальных валют в современной платежной системе // Вестник СПбГУ. Серия 5: Экономика. 2017. № 1. С. 119-140.

Николайчук О.А. Электронная валюта в свете современных правовых и экономических вызовов // JER. 2017. № 1. С. 142-154.

Пряников М.М., Чугунов А.В. Блокчейн как коммуникационная основа формирования цифровой экономики: преимущества и проблемы // International Journal of Open Information Technologies. 2017. № 6. C. 49-55.

Роббек A. E. Bitcoin как явление в мировой экономике // Вестник СВФУ. 2014 № 6. С. 114-118.

Степанова Д.И., Николаева Т.Е., Иволгина Н.В. Особенности организации и направления развития криптовалютных платежных систем // Финансы и кредит. 2016. № 10. С. 33-45.

Шестопалова А. В. Биткоин как новый этап либерализации финансовой сферы // Контуры глобальных трансформаций: политика, экономика, право. 2016. № 2. C. 22-31.

Adhami S., Giudici G., Martinazzi S. Why do business go crypto? An empirical analysis of initial coin offerings. 20.10.2017. [Эл. pecypc]. URL: https://papers.ssrn. com/sol3/papers.cfm?abstract_id=3046209 (дата обращения: 05.11.2017).

Conley J.P. Blockchain and the Economics of Crypto-tokens and Initial Coin Offerings. 06.06.2017. URL: http://www.accessecon.com/Pubs/VUECON/ VUECON-17-00008.pdf (дата обращения: 10.11.2017).

Venegas $P$. Initial coin offering (ICO) risk, value and cost in blockchain trustless crypto markets. 04.08.2017 [Эл. pecypc]. URL: https://papers.ssrn.com/sol3/papers. cfm?abstract id=3012238 (дата обращения: 20.11.2017).

Yadav $M$. Exploring signals for investing in an initial coin offering (ICO) 01.09.2017. [Эл. peсурc]. URL: https://papers.ssrn.com/sol3/papers.cfm?abstract $\mathrm{id}=3037106$ (дата обращения: 15.11.2017).

Статья поступила 17.10.2017. 


\section{Summary}

Obukhova E.A., Novosibirsk State University, Novosibirsk

\section{ICO, as a Modern Method of High-Tech Projects Financing}

Attraction of investments is one of the most significant stages for management at any phase of the life cycle of a business project. Recently, in addition to traditional fundraising channels, such relatively new ways of attracting financing, such as crowdfunding and initial placement of tokens (ICO - initial coin offering), have become widespread. Most often along this path are the teams involved in the implementation of high-tech projects. The growing interest of investors is fueled by the rapid growth of the rate of crypto-currencies, as well as by the policies of a number of leading countries, supporting circulation of crypto-currencies and transactions with them.

This article reviews the world experience of ICO, SWOT-analysis of this mechanism of attracting investments, as well as examples from real economic practice of recent years, illustrating the possibilities and limitations of using this method. Taking into account the analysis, several scenarios for the development of technologies for the creation and use of crypto-currencies have been formulated, and the prospects for the implementation of the ICO, based on their release, have been evaluated.

Crypto-currency, ICO, blockchain, bitcoin, token, fundraising, investments, SWOTanalysis

\section{References}

Kochergin D.A. (2017). Mesto i rol' virtual'nyh valjut v sovremennoj platezhnoj sisteme. Vestnik SPbGU. Serija 5: Jekonomika [St Petersburg University Journal of Economic Studies]. No.1. Pp. 119-140 (In Russ.).

Nikolajchuk O.A. (2017) Jelektronnaja valjuta v svete sovremennyh pravovyh i jekonomicheskih vyzovov. Voprosy regulirovanija jekonomiki [Journal of Economic Regulation]. No.1. Pp. 142-154 (In Russ.).

Prjanikov M.M., Chugunov A.V. (2017). Blokchejn kak kommunikacionnaja osnova formirovanija cifrovoj jekonomiki: preimushhestva i problemy. International Journal of Open Information Technologies. No.6. Pp. 49-55 (In Russ.).

Robbek A.E. (2014). Bitcoin kak javlenie v mirovoj jekonomike. Vestnik SVFU [Vestnik of NEFU]. No.6. Pp. 114-118 (In Russ.).

Stepanova D.I., Nikolaeva T.E., Ivolgina N.V. (2016). Osobennosti organizacii i napravlenija razvitija kriptovaljutnyh platezhnyh system. Finansy $i$ kredit [Finance and credit]. No.10. Pp. 33-45 (In Russ.).

Shestopalova A.V. (2016). Bitkoin kak novyj jetap liberalizacii finansovoj sfery. Kontury global'nyh transformacij: politika, jekonomika, pravo [Outlines of global transformations: politics, economics, law]. No.2. Pp. 22-31 (In Russ.).

Adhami S., Giudici G., Martinazzi S. (2017). Why do business go crypto? An empirical analysis of initial coin offerings. Available at: https://papers.ssrn.com/sol3/ papers.cfm?abstract_id=3046209 (accessed 05.11.2017).

Conley J.P. (2017). Blockchain and the Economics of Crypto-tokens and Initial Coin Offerings. Available at: http://www.accessecon.com/Pubs/VUECON/ VUECON-17-00008.pdf (accessed 10.11.2017).

Venegas P. (2017) Initial coin offering (ICO) risk, value and cost in blockchain trustless crypto markets. Available at: https://papers.ssrn.com/sol3/papers.cfm?abstract $\mathrm{id}=3012238$ (accessed 20.11.2017).

Yadav M. (2017). Exploring signals for investing in an initial coin offering (ICO). Available at: https://papers.ssrn.com/sol3/papers.cfm?abstract_id=3037106 (accessed 15.11.2017). 